\title{
Femoroasetabular sıkışmada tedavi algoritması
}

\author{
Treatment algorithms for femoroacetabular impingement
}

\author{
Kadir Büyükdoğan, Bülent Atilla
}

Hacettepe Üniversitesi Tıp Fakültesi, Ortopedi ve Travmatoloji Anabilim Dalı, Ankara

\begin{abstract}
Femoroasetabular sıkışma, kalça eklemi etrafında anatomik uyumsuzluklardan kaynaklanan mekanik patolojiyi ifade eder. Bu anatomik uyumsuzluklar tedavi edilemezse kıkırdak hasarına yol açabilir. Femoroasetabular sıkışmanın kalça osteoartritine neden olan faktörler arasında gösterilmesiyle beraber, son zamanlarda bu deformitenin tedavi seçenekleri hızla gelişmiştir. Femoroasetabular sıkışmanın cerrahi tedavisi belirlenirken, deformitenin şiddeti, tipi ve konumu göz önünde bulundurulur. Derlememiz, femoroasetabular sıkışmanın tedavisi için geliştirilen güncel tedavi seçeneklerini gözden geçirmektedir.
\end{abstract}

Anahtar sözcükler: femoroasetabular sıkışma; osteoartrit; kalça artroskopisi
Femoroacetabular impingement is a pathomechanical syndrome describing abnormal anatomic relationships within the hip joint that may lead to articular damage. In recent years, femoroacetabular impingement has been recognised as a significant contributing factor in the aetiology of osteoarthritis. As a result, treatment options for femoroacetabular impingement are evolving rapidly, and both open and arthroscopic techniques demonstrate significant promise. Treatment planning depends on the type, location, and severity of deformity. This review provides a summary of the recent techniques that have been developed for the treatment of femoroacetabular impingement.

Key words: femoroacetabular impingement; osteoarthritis; hip arthroscopy
F emoroasetabular eklem patoanatomisinin ve yaralanma modellerinin son zamanlarda daha iyi anlaşılması, kalça eklemi disfonksiyonunun, hastalığın erken evrelerinde fark edilmesine, tanımlanmasına ve hatta genç yaşta tedavi edilmesine olanak sağlamıştır. Femoroasetabular sıkışma (FAS), femurun baş-boyun bileşkesinde veya asetabulumdaki morfolojik değişikliklere bağlı olarak ortaya çıkar. Bu normal olmayan morfoloji nedeniyle, eklemin fizyolojik hareketleri sonucu, femur boynu asetabulum kenarına temas eder. Bu tekrarlayan travma, zaman içinde labrumda yaralanmaya ve eklem kıkırdağında delaminasyona neden olur. ${ }^{[1,2]}$ Bu morfolojik değişikliklerin doğal seyri hala net olarak aydınlatılmış olmasa da, tedavi edilmemesi durumunda osteoartrite (OA) neden olacağı öngörülmektedir. ${ }^{[1]}$ Bu nedenle, FAS tedavisindeki araştırmalar son dönemde giderek ivme kazanmaktadır. Derlememiz, femoroasetabular sıkışmanın tedavisindeki güncel yaklaşımları ve cerrahi seçenekleri gözden geçirmektedir.

\section{TEDAVI PLANLAMASI}

FAS, kalça ağrısı nedeni değil, kalçada zaman içinde ağrıya yol açacak eklem içi patolojilere zemin hazırlayan bir morfolojik değişikliktir. ${ }^{[3]}$ Bu nedenle, hasta FAS ön tanısıyla değerlendirilirken, kalçada ağrıya neden olan eklem içi ve dışı patolojiler göz önünde bulundurulmalıdır. Eklem içi serbest cisim, dejeneratif labrum yırtıkları gibi eklem içi patolojiler ve iliopsoas tendiniti, adduktor ve piriformis kas zedelenmeleri, trokanterik bursit ve gluteal tendinopatiler gibi eklem dışı patolojiler de, kalça ağrısına neden olarak karşımıza çıkabilir. Ayrıca, rektus abdominis gerilmeleri ve kasık hernilerinin de kalça ağrısını taklit ettiği unutulmamalıdır. Bu nedenle, ağrının FAS'tan kaynaklandığına, klinik öykü, muayene ve radyolojik değerlendirme ile karar verilmeli ve tedavi buna göre yönlendirilmelidir.

FAS tanısı konulduktan sonra tedavi, hastanın şikayetlerine göre şekillendirilir. Çoğu hasta, FAS için tanımlanmış morfolojik değişikliklere sahip

- Illetişim adresi: Dr. Bülent Atilla, Hacettepe Üniversitesi Tıp Fakültesi, Ortopedi ve Travmatoloji Anabilim Dalı, Sıhhiye, Ankara Tel: 0532 - 2928717 e-posta: batilla62@gmail.com

- Geliș tarihi: 10 Ocak 2016 Kabul tarihi: 10 Ocak 2016 
olmasına rağmen, uzun dönem asemptomatik kalabilir. Dolayısıyla, çeşitli nedenlerle saptanan kalça çevresi ağrıların FAS etiyolojisine ait olduğu ispatlanmalıdır. Aynı zamanda, bu hastalardaki morfolojik değişiklikleri düzeltmenin, OA'nın doğal seyri üzerinde ne kadar etkili olduğu henüz bilinmemektedir. FAS tedavisindeki seçenekler sadece cerrahi yaklaşım ile kısıtlı kalmamış, kalça ekleminin iyileşme kapasitesini ve hastanın fonksiyonel durumunu da göz önünde bulundurarak, gelişmeye devam etmektedir. Tedavideki amaç, sadace OA oluşumunu engellemek değil, mevcut semptomları en aza indirerek uzun dönemde fonksiyonel bir kalça eklemi elde etmektir.

Çoğu iskelet sistemi yaralanmalarının tedavisine benzer olarak, semptomatik FAS hastalarının tedavisinde de ilk basamağı istirahat ve anti-inflamatuvar ilaçlar oluşturur. Bu aşamada, ayrıcı tanıya önem verilerek, eklem dışı kalça ağrıları ve yansıyan ağrılar değerlendirilir. Uygulamalar her ne kadar morfolojik değişiklikleri düzeltmese de, konservatif tedavideki amaç, hastaları aseptomatik duruma getirebilmektir. Bu nedenle, fizik tedavi egzersizleri ve aktivite modifikasyonları önerilir. Fizik tedavide dikkat edilmesi gereken nokta, kalça ekleminin hareket açıklığını arttırmak değil, hastanın semptomlarını şiddetlendiren hareketleri engellemektir. Sonraki basamak ise, eklemin bu hareketlere uyumunu sağlayacak şekilde, kas germe ve kuvvetlendirme, nöromusküler koordinasyon ve denge egzersizlerini içerir. ${ }^{[4]}$ Literatürde, FAS'ın konservatif yöntem ile tedavi sonuçları oldukça kısıtlıdır. Az sayıda hasta grubunu içeren çalışmalarda, fizik tedavi ile takip edilen hastaların tedavi sonucunda aktivite düzeyinde artma ve cerrahi tedavi ihtiyacında azalma belirtilmiştir. ${ }^{[5]}$ Ancak, ilk başta konservatif tedaviden yarar gören hastaların, uzun dönem sonuçlarının daha geniş kapsamlı çalışmalar ile belirlenmesi gerekir.

FAS'ın cerrahi tedavi yöntemi, kalçadaki morfolojik değişikliklere göre belirlenir. Femur başı asetabulum ilişkisi ve kondrolabral bileşke, FAS'ın temel patolojisini oluşturur. Pincer tipi FAS'ta, kıkırdak hasarı ile beraber, labrumda dejenerasyon ve ossifikasyon vardır. Cam tipi FAS ise, labrum çoğu zaman sağlam görünümdedir, ancak hemen bitişiğindeki kıkırdakta delaminasyon görülür.

Pincer tipi FAS'ta cerrahi tedavi hedefi, asetabulum kenarı ile femur boynu arasındaki teması ortadan kaldırmaktır. Cerrahi teknik ise, morfolojik değişikliğin tipine göre belirlenir. Asetabulumun anteriordan daha fazla örtündüğü durumlarda, asetabular rim tıraşlanması uygulanabilir. Labruma yaklaşım ise, duruma göre, debridmanı, onarımı ve rekonstrüksiyonu içerir. Asetabulumun çepeçevre aşırı örtündüğü koksa profunda veya koksa protrüzyo gibi durumlarda, asetabulumun bütün kenarının tıraşlanması gerekebilir. Asetabulumun retrovert olduğu daha ağır deformitelerde ise, asetabular re-oryantasyon cerrahisi uygulanabilir. Cam tipi FAS'ta ise, amaç baş-boyun bileşkesindeki fazla kemik ve kıkırdağı eksize ederek, femur başının sferisitesini tekrar kazanmaktır. Günümüzde, FAS tedavisinde farklı yaklaşımlar bulunmaktadır. Anterior mini-artrotomi, artroskopik destekli mini-artrotomi ve güvenli cerrahi dislokasyon, FAS tedavisinde önemli yer tutan uygulamalardır.

\section{KALÇANIN GÜVENLI CERRAHI DISLOKASYONU}

FAS tanımlaması nispeten güncel bir tanı olmasına rağmen, 1930'lu yıllarda Smith-Petersen tarafından, asetabular protrüzyo ve koksa plana için asetabular tıraşlama ve proksimal femoral osteotomi gibi açık teknikler bildirmiştir. ${ }^{[6]}$ FAS'ın patolojik bir durum olarak tanımlanması ile beraber, 1990'larda Ganz, FAS tedavisi için transtrokanterik yaklaşım ile kalça ekleminin cerrahi dislokasyonu tanıtmıştır. ${ }^{[7]}$ Bu yöntem, cam tipi sıkışmada baş boyun ofsetinin restorasyonu, kondrolabral lezyonlarda labrum fiksasyonu ve delamine kıkırdak dokusunun fiksasyonu endikasyonları ile uygulanabilir. Pincer tipi sıkışmada ise, eğer posterior duvar örtünmesi yeterli ise, anterior duvarın tıraşlanması ve labral re-fiksasyon amaçlı kullanılabilir. Pediatrik dönem kalça displazilerinin neden oldu sıkışmalarda da tercih edilen bir yöntem olan cerrahi dislokasyon, Pethes sekellerinde trokanterik parçanın daha distale fikse edilerek göreceli femur boyun uzatması ile, femur başı epifiz kaymasında ise subkapital korreksiyon osteotomisi ile kombine edilebilir.

Teknik olarak bu yöntemde, posterolateral yaklaşım ile gluteus medius ve vastus lateralisin yapışma yerleri korunarak, trokanterik osteotomi yapılır. Obturator eksternus kası ve mediyal sirkumfleks arter korunarak kapsül ekpoze edilir. Z şeklindeki kapsülotomi sonrası, femur başı anteriora disloke edilir. Bu açık cerrahi ile, asetabulum ve labrumun $360^{\circ}$ görüntülenmesi mümkün olmaktadır (Şekil 1). Femura baş-boyun bileşkesinin ofseti ve femur başının kıkırdak hasarı değerlendirilir. Sferik femur başı ile eliptik boyun arasındaki konkav geçişi tekrar elde edebilmek için, kondro-osseöz kemik büyümesi rezeke edilir. Femur baş-boyun bileşkesinin morfolojik korreksiyonunda, boynun fazla rezeksiyonundan kaçınmak gerekir. Rezeksiyonun güvenli sınırını belirlemek için, günümüzde kesin kılavuzlar yoktur. Ancak, \%30 ve daha fazla rezeksiyon yapılan kalçalarda proksimal femurun yük taşıma kapasitesinin azaldığı göz önünde bulundurulmalıdır. ${ }^{[8]}$ Asetabulum da aynı şekilde, kıkırdak hasarı ve labrum hasarı için 

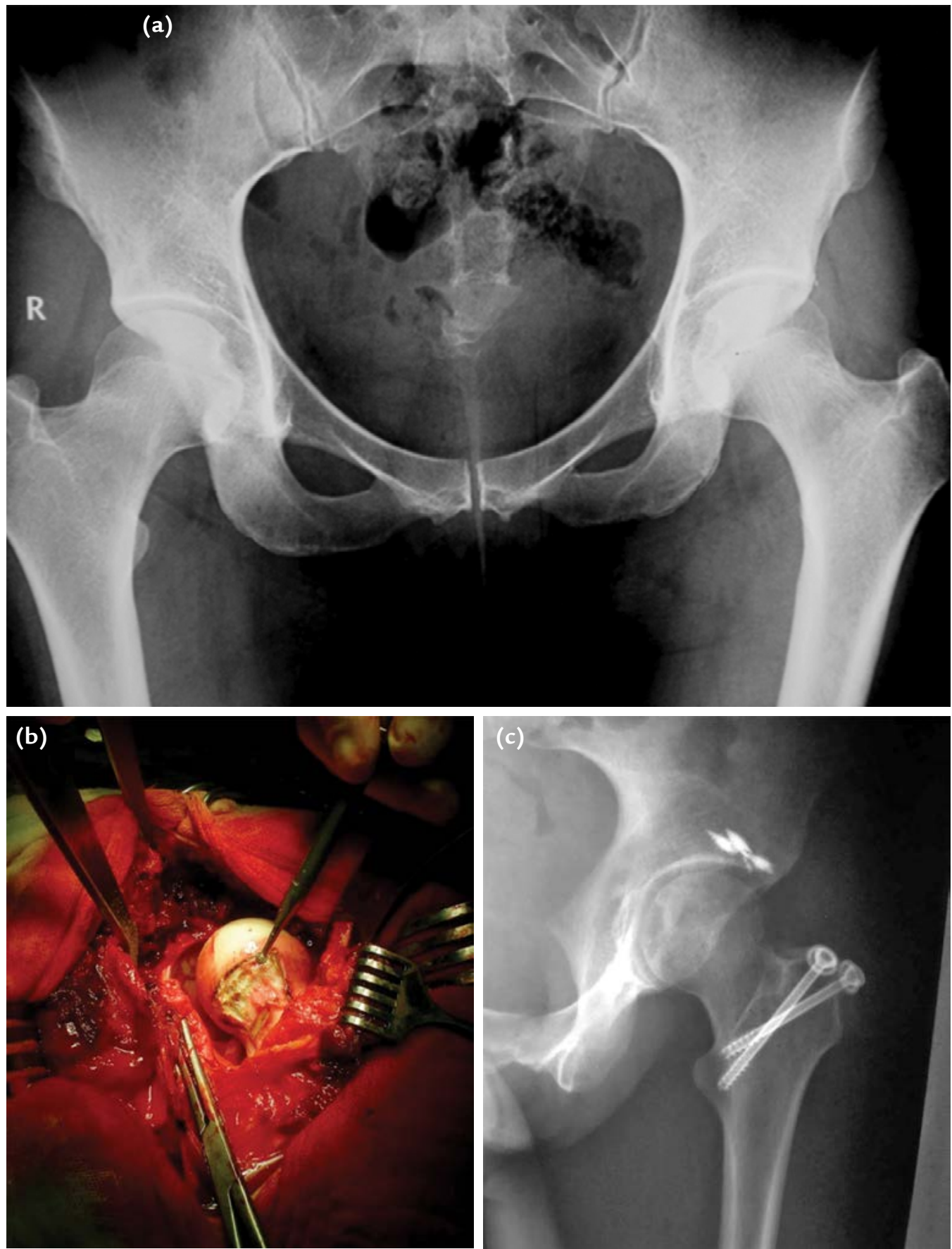

Şekil 1. a-c. Yirmi yedi yaşında kadın hastanın sol kalçasında cam tipi FAS deformitesi (a). Femur başının cerrahi dislokasyonu sonrası femur boyunun anterolateralindeki deformitenin rezeksiyonu (b). Ameliyat sonrası grafide, trokanterik parçanın fiksasyonu ve labrumun çapa dikişleri ile tespiti (c).

değerlendirilir. Labral ilerletme ile asetabular kıkırdak hasarının kapsamı belirlenebilir. Labrum patolojilerin eşlik ettiği durumlarda, labrumun eksizyonu yerine, mümkün olduğunca onarılmasının dejeneratif süreci geciktireceği unutulmamalıdır. ${ }^{[9]}$
Bu yöntemin sık rastlanılan komplikasyonları arasında, femur başının avasküler nekrozu, siyatik nöropati, heterotopik ossifikasyon, femur boyun kırığı ve trokanterik kaynamama bulunur. En ciddi komplikasyon olan avasküler nekrozdan kaçınmak için, femur 

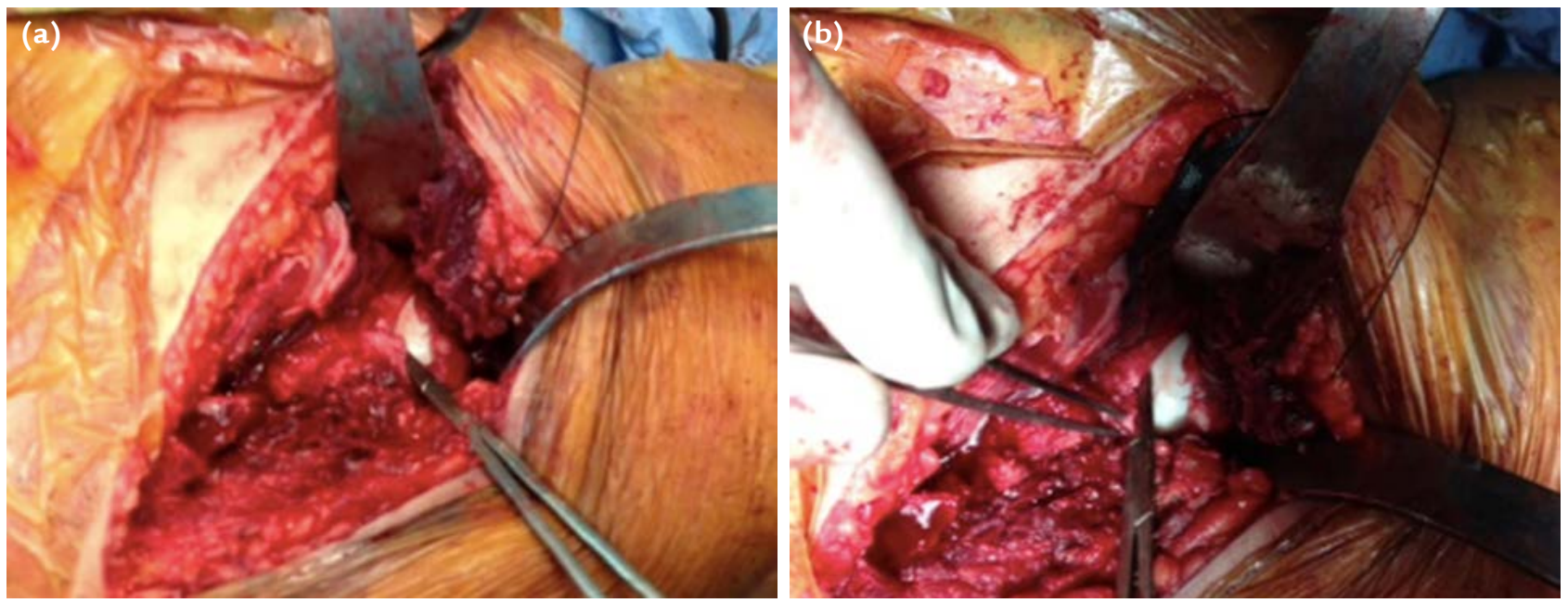

Şekil 2. a-b. Displastik zeminde FAS'ı olan ve posterior örtünmesi yetersiz olan bir hastamıza periasetabular osteotomi uygulandıktan sonra, ek artrotomi ile femur boynuna osteokondroplasti uygulaması.

başının vasküler anatomisine hakim olmak gerekir. Trokanterik kaynamamayı engellemek için basamaklı osteotomi yapılması, heretopik ossifikasyonu engellemek için de dislokasyonun yeterli miktarda yumuşak doku gevşetmesi sonrası yapılması önerilir. Eklem sertliği oluşmaması için, erken dönemde harekete başlanmalıdır.

\section{PERIASETABULAR OSTEOTOMI}

Ciddi asetabular retroversiyonu olan bazı hastalar, periasetabular osteotomiden (PAO) yarar görebilirler. Aşırı retroversiyon, genelde posterior duvar ve crossover belirtisinin olduğu, pelvis röntgeninde iskial çıkıntının belirginleştiği kalçalarda, hemipelvisin tamamını içeren deformiteleri ifade eder. PAO'da, ilium, iskium, superior pubik ramus ve posterior kolon osteotomisi uygulanır ve asetabular fragman mobilize edilir. Lateral ve posterior örtünme, asetabular inklinasyon ve horizontal kalça merkezi göz önünde bulundurularak fragman fikse edilir. Sonuç olarak PAO, asetabulum yüzeyi re-oryente ederek anteriordaki fazla örtünmeyi azaltır ve posterior örtünme defektini restore eder (Şekil 2). $\mathrm{Bu}$ yöntemde, eş zamanlı olarak anterior artrotomi ile kombine edilebilir ve labrum re-fiksasyonu, femoral osteokondroplasti, anteroinferior iliak çıkıntı osteoplastisi ve anterior trokanterik osteoplasti gibi ek işlemlerin uygulanmasına olanak sağlayabilir. Aynı zamanda, eklem dışı rezidüel patolojilere yönelik varus veya valgus üreten proksimal femoral osteotomiler de eş zamanlı olarak uygulanabilir. FAS nedeniyle PAO uygulanacak hastaların, 40 yaş altında ve uygun kiloda olmasına, yeterli eklem hareket açıklığına ve eklem aralığına sahip olmasına dikkat edilmelidir; derin ven trombozu (DVT), heterotopik ossifikasyon, kanama ve enfeksiyon profilaksisi unutulmamalıdır.

Birçok çalışmada, FAS'ın açık cerrahi tedavisi ile, hastalarda erken dönemde fonksiyonel iyileşme bildirilmiştir. Ancak, bu yöntemlerin öğrenme eğrisi uzundur ve trokanterik kaynamama, trokanterik bursit, hasta memnuniyetsizliği, ${ }^{[10]}$ rekürren labral yırtık, dejenerasyonun ilerlemesi ve artroplastiye geçişin hızlanması gibi komplikasyonlar bildirilmiştir. ${ }^{[11]}$ Bu nedenle, son dönemlerde daha az invaziv cerrahi yöntemlere ilgi artmıştır.

\section{KOMBINE ANTERIOR MINI-ARTROTOMI VE ARTROSKOPIK YAKLAŞIM}

Anterior mini-artrotomi, son dönemlerde, erken dönem anterolateral FAS tedavisinde cerrahi dislokasyona alternatif bir yaklaşım olarak gündeme gelmiştir. Bu yöntem ile, eklem disloke edilmeden başboyun bileşkesinin ve asetabulumun anterior bölgesi ekspoze edilir. ${ }^{[12]}$ Smith-Petersen intervalini kullanan ve trokanterik osteotomiye gerek duymayan minimal anterior yaklaşım ile, baş-boyun bileşkesine osteokondroplasti uygulanabilir ve rezeksiyon miktarı, gerekirse floroskopik olarak kontrol edilebilir (Şekil 3). Anterolateral asetabular rim ve kalsifiye labruma da bu yöntem ile müdahale edilebilir. Direkt ulaşım sağlanamayan merkezi bölgelere ise, artroskopik yöntem ile müdahale edilebilir. Bu yöntemin erken dönem sonuçları, tam artroskopik yaklaşım ile benzer sonuçlara sahiptir. ${ }^{[12,13]}$ Ancak bu yöntem, posteroinferior 


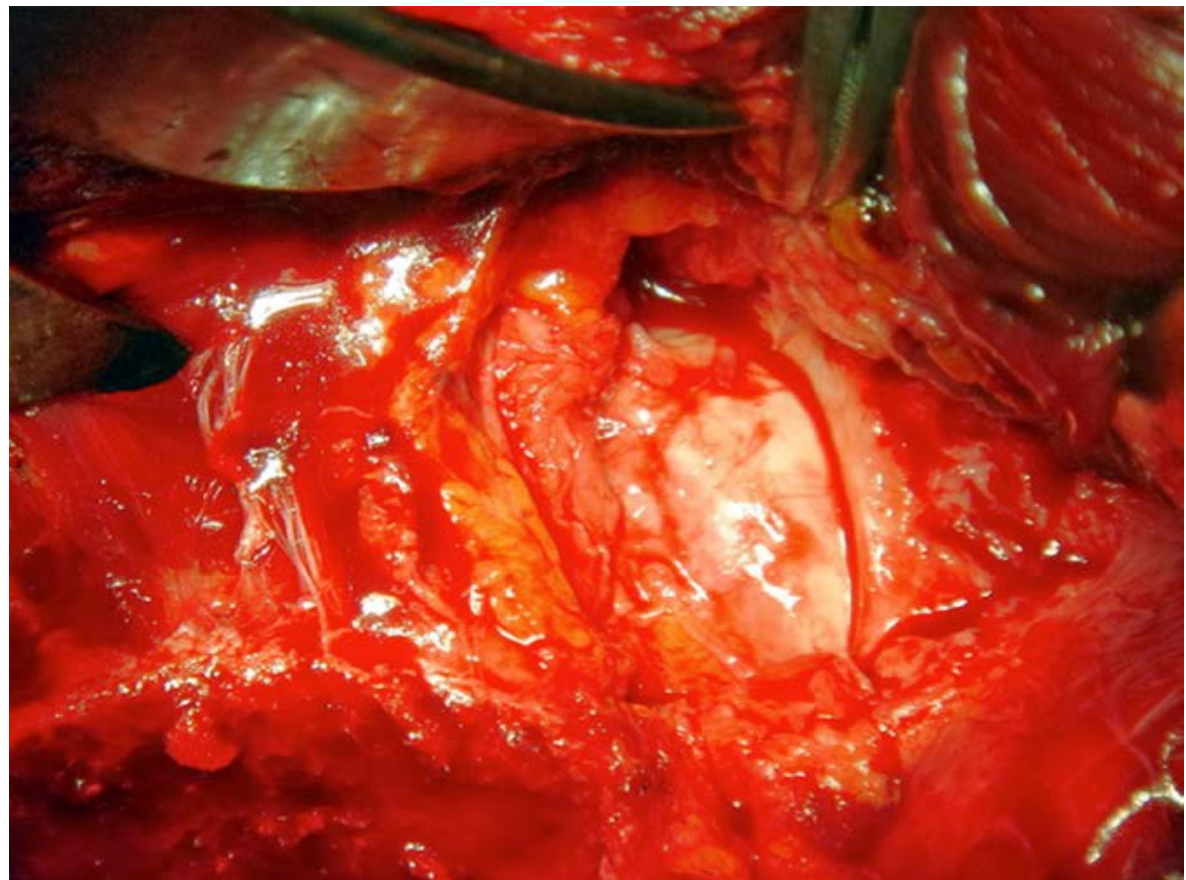

Şekil 3. Smith-Petersen yaklaşımı ile kalça eklemi anterioruna ulaşılması ve kapsülotomi sonrası anteriordaki deformitenin korreksiyonu.

patolojiler için ve koksa profunda gibi sirkumferansiyel patolojiler için uygun bir yöntem değildir. Günümüzde artroskopik enstrümanların daha da gelişmesi ile, bu yöntem yavaş yavaş terk edilmekte ve tam artoskopik yaklaşıma geçilmektedir. ${ }^{[14]}$

\section{KALÇA ARTROSKOPisi}

Artroskopi tekniğinin ve enstrümantasyonun gelişimi ile beraber, kalça artroskopisi endikasyonları da genişlemektedir; 70'li yılların başında tanıtılan bu yöntemin günümüzde endikasyonları, sadece labrum yırtıkları ve eklem içi patolojiler ile sınırı kalmaz. FAS tedavisindeki en güncel yöntemlerden biri olan artroskopik yaklaşım ile, asetabular tıraşlama ve femur boynuna osteokondroplasti uygulanabilir ve bu yöntemin popülaritesi giderek artmaktadır. ${ }^{[15]}$ Çünkü, artroskopik teknik, yumuşak doku hasarını ve mediyal sirkumfleks arter yaralanma riskini en aza indirir. illk dönemlerde lateral pozisyonda uygulanan bu yöntem, günümüzde, patoloji en sık anterior bölgede olduğu için supin pozisyonda yapılmaktadır. Kalça artroskopisinin açık cerrahiye oranla daha az morbidite oluşturması, daha hızlı rehabilitasyon sağlaması, enfeksiyon oranının düşük olması gibi birçok avantajı bulunmaktadır. ${ }^{[16]}$

Fokal ve hafifglobal retroversiyon, os asetabula, subspinal sıkışma, hafif koksa profunda gibi patolojilerin neden olduğu pincer tipi sıkışmalar, artroskopik yöntemlerle tedavi edilebilir. Bu deformitede, asetabular rime müdahale edebilmek için, labrum mümkün olduğunca serbestleştirilir; operasyon öncesi planlanan şekilde, anterior rim tıraşlandıktan sonra, labrumun çapa dikişler ile re-fiksasyonu uygulanır (Şekil 4). Bu nokta$\mathrm{da}$, anteriordan fazla rezeksiyonun iyatrojenik instabiliteye neden olabileceği ve labrum dikişlerinin, omuz labrumundaki sirkumferansiyel sütürlerin aksine, mattress tekniği ile atılmasına dikkat edilmelidir. ${ }^{[17]}$

Femoral baş boyun bileşkesinin, anterior, superioposterior ve inferio-posteriordaki lezyonların, hafif femoral retroversiyonun ve femur başı epifız kaymasının (slip açısı $<30-35^{\circ}$ ) neden olduğu cam tipi sıkışmalar da tam artroskopik tedavi endikasyonlarını oluşturur. Bu deformitelerde rezeksiyon, ameliyat öncesi planlanan lokalizasyonda ve miktarda, kıkırdak kenarından başlayıp distale doğru uzanır. Femur boynunda stres kırığı oluşmaması için, rezeksiyon miktarı, boyun genişliğinin \%30'unu geçmemelidir. Hasta lateral pozisyonda iken anteroinferior lezyonlar, hasta supin pozisyonda iken superior lezyonlar daha az oranda rezeke edilmektedir. Artroskopik yöntem ile yapılan osteokondroplastinin, açık cerrahi tekniğe benzer oranda morfolojik korreksiyon sağladığı görülmüştür. Yakın zamanda yapılan bir çalışmada bu iki yöntem karşılaştırılmış ve her iki yöntemde de benzer oranda, $\alpha$ açısında ve baş-boyun 

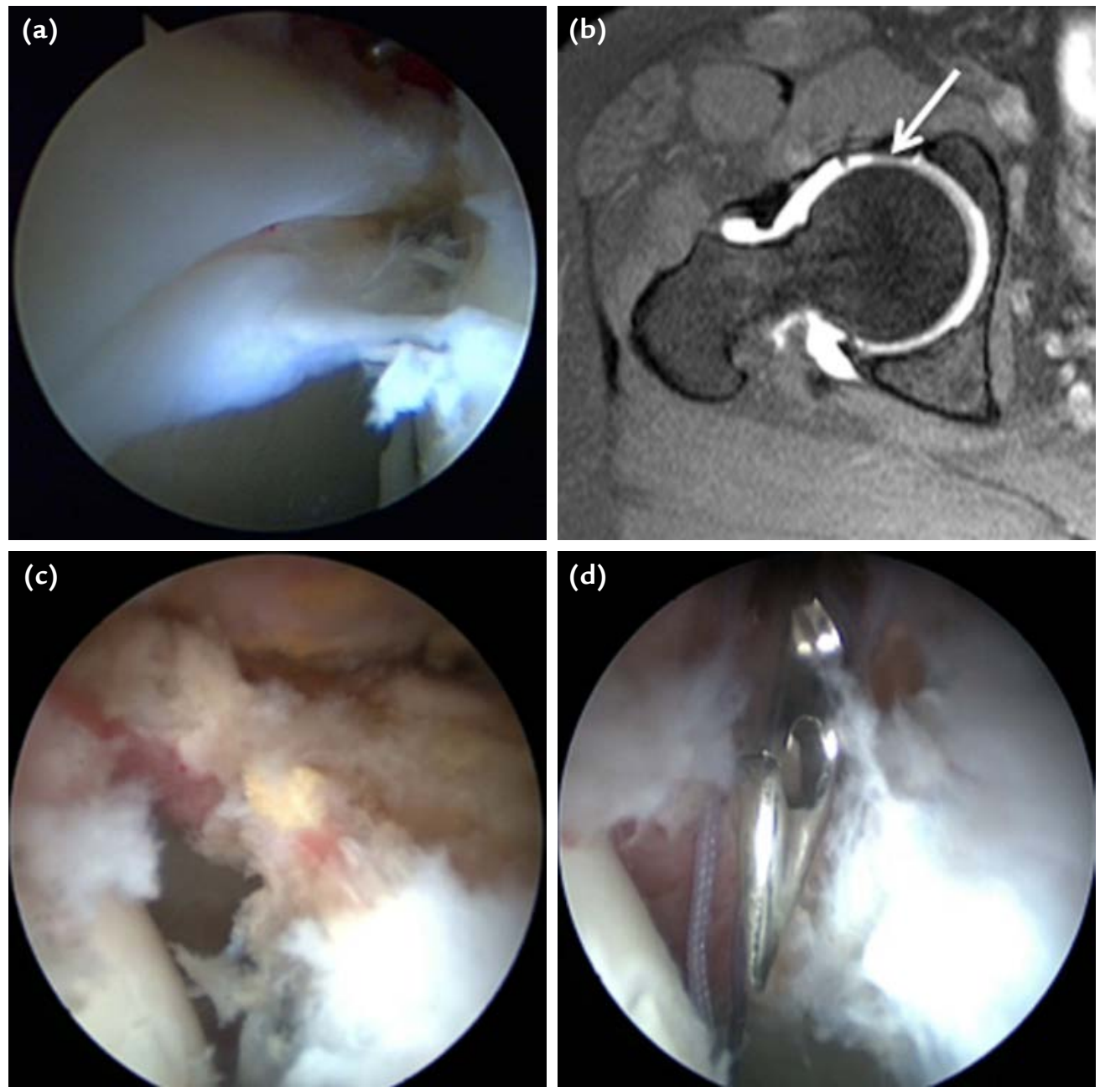

Şekil 4 a-d. FAS nedeniyle tedavi ettiğimiz hastanın sağ kalçasında saat 10 yönünde bulunan labrum yırtığının artroskopik görüntüsü (a) ve MR bulgusu (b). Asetabulum duvarının artroskopik olarak tıraşlanmış hali (c) ve labrumun refiksasyonu (d). (Dr. Ö Ahmet Atay'ın izni ile kullanılmıştır.)

ofsetinde düzelme görülmüş, ancak superiordaki korreksiyon oranı açık cerrahide daha fazla bulunmuştur. [18] Eklem sertliğinin eşlik ettiği durumlarda, artroskopik olarak terapötik kapsülotomi uygulanabilir; ancak, kapsüler laksitesi olan veya işlem esnasında kapsül hasarı oluşan hastalardaki hafif instabiliteyi engellemek için, kapsülün mümkün olduğunca onarılması gerekmektedir. ${ }^{[19]}$

Ancak FAS'ta, kalçanın bütün deformitelerine artroskopik yöntem ile müdahale etmek mümkün değildir. Femur başının ve asetabulumun posteriorundaki ve koksa profunda gibi lezyonlara artroskopik yöntemlerle müdahale etmek mümkün değildir.

İleri derecede femur başı epifiz kayması olan (slip açısı $>30-35^{\circ}$ ), asetabular displazi, ciddi protrüzyo,
Perthes sekeli, geniş kıkırdak defekti ve asetabulum retroversiyonu olan hastalarda kalça artoskopisi uygun değildir; bu hastalara açık teknikler ile müdahale etmek gerekir.

Son zamanlarda kalça biyomekaniğinin ve anatomisinin daha iyi anlaşılması ve cerrahi tekniklerdeki yenilikler ile beraber, artroskopik yöntemler FAS tedavisinde daha yaygın olarak kullanıma girmiştir. Son 10 yılda giderek artan bir ivme ile kullanılan artroskopik yöntemler, günümüzde, FAS için açık teknikler yerine tercih edilen bir yöntem olmuştur. Enstrümantasyon, görüntüleme ve eklem kapsülüne yönelik işlemlerin gelişmesi ile beraber, ileri dönemde artroskopik yöntemlerin FAS'a eşlik eden eklem içi patolojilerin tedavisinde de kullanılacağı öngörülebilir. 


\section{FAS Tedavi Algoritması}

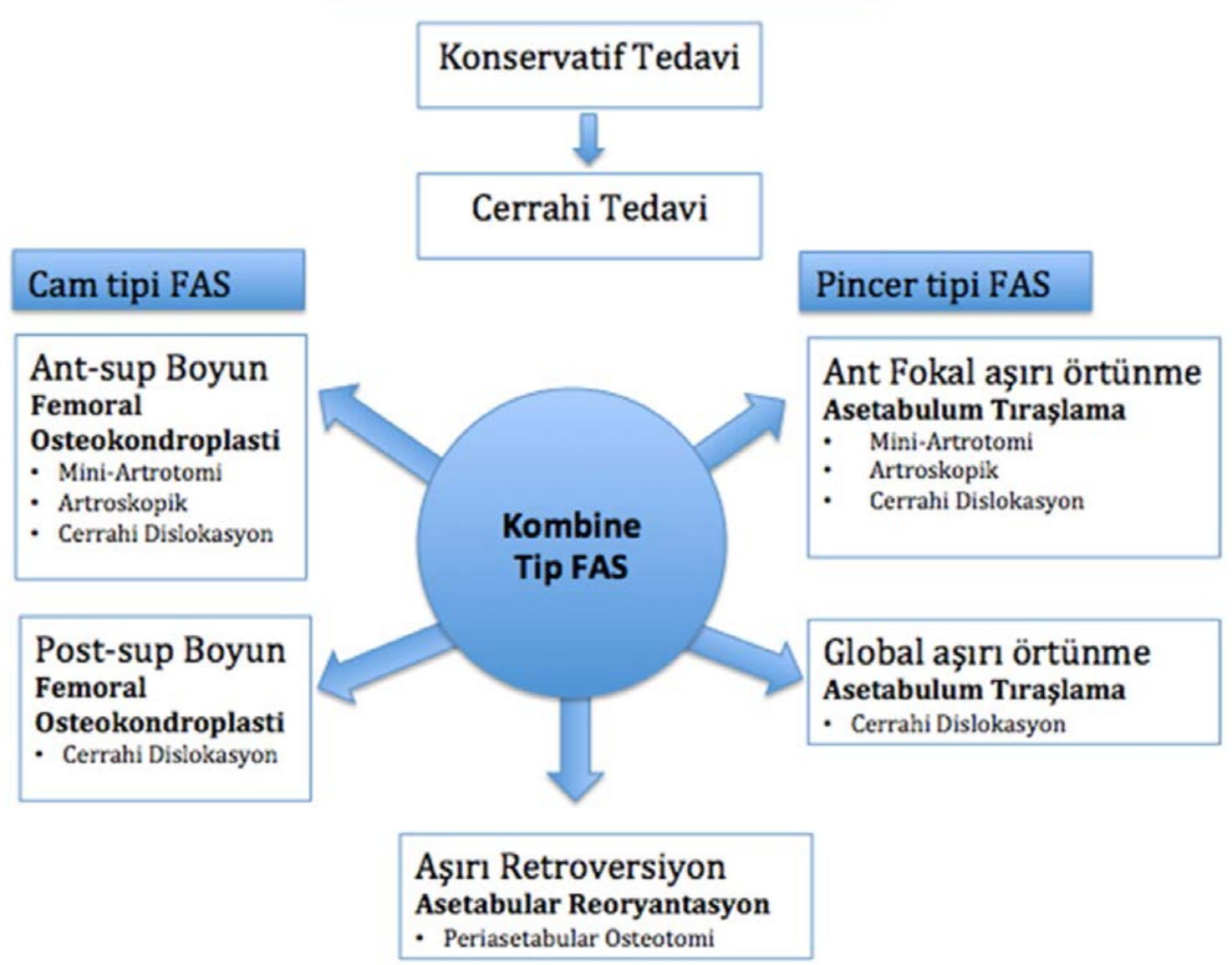

Şekil 5. Femoroasetabular sıkışma için morfolojik patolojiye göre tedavi algoritması.

\section{TARTIŞMA}

FAS, yeni tanımlanmış bir patoloji olmakla beraber, bu patolojinin tanı, tedavi ve görüntüleme yöntemleri giderek somutlaşmaktadır. FAS'ın tedavi planlaması yapılırken, hastanın öyküsü, fizik muayenesi ve radyolojik değerlendirmesi dikkatli yapılmalıdır. Öncelikle, anti-inflamatuvar ilaçları ve aktivite modifikasyonunu içeren konservatif tedavi yöntemleri uygulanmalıdır. Ancak, devam eden FAS kıkırdak ve labrum hasarına yol açacağı için, semptomların düzelmemesi halinde cerrahi tedavi düşünülmelidir. Cerrahi tedavi, hastanın şikayetlerine ve patolojinin morfolojisine göre şekillenmelidir (Şekil 5). Cam tipi deformitelerde, patoloji sıklıkla anterosuperior baş-boyun bileşkesinde olduğu için, artroskopik olarak müdahele edilebilir. Ancak, deformite daha posterior yerleşimli ise artroskopik olarak yaklaşım mümkün olmamaktadır; bu durumda, açık cerrahi tedavi tercih edilmelidir. Aynı şekilde, Perthes gibi kompleks proksimal femur deformitelerinin olduğu durumlarda da açık cerrahi tedavi öne çıkmaktadır. Pincer tipi deformitelerde planlama yapılırken, asetabulum retroversiyonu ve çevresel aşırı örtünme olup olmadığı öncelikli olarak değerlendirilir. Ciddi retroversiyonu olan ve posterior duvar örtünmesinin yetersiz olduğu durumlarda, periasetabular osteotomi yapılması uygun bir seçenektir. Posterior duvar örtünmesinin yeterli olduğu ve anterosuperior asetabulumda fokal lezyonu olan hastalarda, açık veya artroskopik olarak, asetabular tıraşlama ve labrum onarımı yapılabilir. Asetabulumu çepeçevre saran aşırı örtünme durumlarında, açık cerrahi yöntemleri tercih edilmelidir. Hem açık hem artroskopik tedavi yöntemlerindeki en sık başarısızlık nedeni ise, altta yatan deformitenin yeterince 
Tablo 1. FAS tedavisinde kullanılan cerrahi yöntemlerin avantajları ve dezavantajları

\begin{tabular}{|c|c|c|}
\hline Cerrahi teknik & Avantaj & Dezavantaj \\
\hline Cerrahi dislokasyon & $\begin{array}{l}\text { Femur başı ve asetabulumun } 360^{\circ} \\
\text { görüntülenmesi. } \\
\text { Traksiyon ihtiyacı yok. }\end{array}$ & $\begin{array}{l}\text { Büyük trokanter osteotomisi. } \\
\text { İnvaziv girişim. }\end{array}$ \\
\hline Kalça artroskopisi & $\begin{array}{l}\text { Minimal invaziv girişim. } \\
\text { Hızlı rehabilitasyon. }\end{array}$ & $\begin{array}{l}\text { Traksiyona bağlı sinir hasarı. } \\
\text { Öğrenme eğrisi uzun. } \\
\text { Posteriora ulaşım kısıtlı. }\end{array}$ \\
\hline Mini-artrotomi & $\begin{array}{l}\text { Traksiyon ihtiyacı yok. } \\
\text { Büyük trokanter osteotomisi yok. } \\
\text { Sıkışma bölgesinin dinamik değerlendirilmesi. } \\
\text { Göreceli minimal invaziv. } \\
\text { Artroskopi ile kombine edilebilir. }\end{array}$ & $\begin{array}{l}\text { Sadece anterior ve posterior baş-boyun } \\
\text { bileşkesine ulaşım. }\end{array}$ \\
\hline Periasetabular osteotomi & $\begin{array}{l}\text { Asetabulumda en fazla korreksiyon. } \\
\text { Traksiyon ihtiyacı yok. } \\
\text { Artrotomi ile eklem içine müdahale }\end{array}$ & $\begin{array}{l}\text { Oldukça invaziv girişim. } \\
\text { Yüksek komplikasyon oranı. } \\
\text { Yavaş rehabilitasyon. }\end{array}$ \\
\hline
\end{tabular}

düzeltilmemesi ve yanlış hasta seçimidir. Eklem aralığı 2 mm'den az olan ve Tönnis Evre 3 hastaların, belirtilen uygulamalardan çok az yarar göreceği göz önünde bulundurulmalıdır. Asetabular kıkırdak lezyonları hastalığın erken döneminde oluşurken, femur başındaki kıkırdak hasarı daha ileri dönemde oluşur. Bu nedenle, femur başında kıkırdak lezyonu oluşmuş hastalara, daha dikkatli tedavi planlaması yapmak gerekir.

FAS'ın açık ve artroskopik tedavi sonuçlarını içeren çalışmaların çoğunda, bulgular umut vadedicidir. Ancak, hangi yöntemin daha başarılı olduğu konusunda yeterli bilgi ve görüş birliği yoktur (Tablo 1). Bu nedenle, FAS'ın tedavisinde, OA gelişmeden uygun cerrahi yönteminin belirlenmesi için, uzun dönemli randomize ileriye dönük çalışmalara ihtiyaç duyulmaktadır.

\section{KAYNAKLAR}

1. Ganz R, Parvizi J, Beck M, Leunig M, Nötzli H, Siebenrock KA. Femoroacetabular impingement: a cause for osteoarthritis of the hip. Clin Orthop Relat Res 2003(417):112-20.

2. Beck M, Kalhor M, Leunig M, Ganz R. Hip morphology influences the pattern of damage to the acetabular cartilage: femoroacetabular impingement as a cause of early osteoarthritis of the hip. J Bone Joint Surg $\mathrm{Br}$ 2005;87(7):1012-8.

3. Byrd JW, Jones KS. Arthroscopic femoroplasty in the management of cam-type femoroacetabular impingement. Clin Orthop Relat Res 2009;467(3):739-46. Crossref

4. Byrd JW, Jones KS. Osteoarthritis caused by an inverted acetabular labrum: radiographic diagnosis and arthroscopic treatment. Arthroscopy 2002;18(7):741-7.

5. Emara K, Samir W, Motasem el H, Ghafar KA. Conservative treatment for mild femoroacetabular impingement. J Orthop Surg (Hong Kong) 2011;19(1):41-5.
6. Smith-Petersen MN. The classic: Treatment of malum coxae senilis, old slipped upper femoral epiphysis, intrapelvic protrusion of the acetabulum, and coxa plana by means of acetabuloplasty 1936. Clin Orthop Relat Res 2009;467(3):608-15. Crossref

7. Ganz R, Gill TJ, Gautier E, Ganz K, Krügel N, Berlemann $U$. Surgical dislocation of the adult hip a technique with full access to the femoral head and acetabulum without the risk of avascular necrosis. J Bone Joint Surg $\mathrm{Br}$ 2001;83(8):1119-24.

8. Mardones RM, Gonzalez C, Chen Q, Zobitz M, Kaufman KR, Trousdale RT. Surgical treatment of femoroacetabular impingement: evaluation of the effect of the size of the resection. J Bone Joint Surg Am 2005;87(2):273-9.

9. Espinosa N, Rothenfluh DA, Beck M, Ganz R, Leunig M. Treatment of femoro-acetabular impingement: preliminary results of labral refixation. J Bone Joint Surg Am 2006;88(5):925-35.

10. Beaule PE, Le Duff MJ, Zaragoza E. Quality of life following femoral head-neck osteochondroplasty for femoroacetabular impingement. J Bone Joint Surg Am 2007;89(4):773-9.

11. Murphy S, Tannast M, Kim YJ, Buly R, Millis MB. Debridement of the adult hip for femoroacetabular impingement: indications and preliminary clinical results. Clin Orthop Relat Res 2004(429):178-81.

12. Clohisy JC, McClure JT. Treatment of anterior femoroacetabular impingement with combined hip arthroscopy and limited anterior decompression. lowa Orthop J 2005;25:164-71.

13. Lincoln M, Johnston K, Muldoon M, Santore R. Combined arthroscopic and modified open approach for cam femoroacetabular impingement: a preliminary experience. Arthroscopy 2009;25(4):392-9. Crossref

14. Laude F, Sariali E, Nogier A. Femoroacetabular impingement treatment using arthroscopy and anterior approach. Clin Orthop Relat Res 2009;467(3):747-52. Crossref

15. Bozic KJ, Chan V, Valone FH 3rd, Feeley BT, Vail TP. Trends in hip arthroscopy utilization in the United States. J Arthroplasty 2013;28(8 Suppl):140-3. Crossref 
16. Philippon MJ, Briggs KK, Yen YM, Kuppersmith DA. Outcomes following hip arthroscopy for femoroacetabular impingement with associated chondrolabral dysfunction: minimum twoyear follow-up. J Bone Joint Surg Br 2009;91(1):16-23. Crossref

17. Larson CM, Giveans MR, Stone RM. Arthroscopic debridement versus refixation of the acetabular labrum associated with femoroacetabular impingement: mean 3.5-year follow-up. Am J Sports Med 2012;40(5):1015-21. Crossref
18. Bedi A, Zaltz I, De La Torre K, Kelly BT. Radiographic comparison of surgical hip dislocation and hip arthroscopy for treatment of cam deformity in femoroacetabular impingement. Am J Sports Med 2011;39 Suppl:20S-8S. Crossref

19. Bedi A, Galano G, Walsh C, Kelly BT. Capsular management during hip arthroscopy: from femoroacetabular impingement to instability. Arthroscopy 2011;27(12):1720-31. Crossref 